\title{
Idiopathic haemorrhagic rupture of the shoulder in destructive disease of the elderly
}

\author{
ANTHONY D WOOLF, ${ }^{1}$ TIM E CAWSTON, ${ }^{2}$ AND PAUL A DIEPPE ${ }^{1}$ \\ From the ${ }^{1}$ Department of Medicine, Bristol Royal Infirmary, Marlborough Street, Bristol; and the $\overrightarrow{0}$ \\ ${ }^{2}$ Rheumatology Research Unit, Addenbrooke's Hospital, Cambridge
}

SUMmarY The cases of two patients with hydroxyapatite crystal associated destructive disease of the shoulder are described who have developed gross haemorrhagic effusions with: spontaneous joint rupture and extensive soft tissue damage. No collagenase activity was found in the synovial fluid. Other possible mechanisms of the destructive process are discussed.

Key words: hydroxyapatite, joint rupture, haemorrhage, collagenase.

There have been several reports describing a destructive arthritis of the elderly affecting the shoulders. ${ }^{1-7}$ More recently, reports have documented similar damage to additional joints, most commonly the knees. ${ }^{18}$ The radiological changes include severe cartilage and bone attrition with joint instability. A relative lack of regenerative changes in subchondral and periarticular bone has been noted. Rupture of the rotator cuff is common when the shoulder is involved, and areas of articular or periarticular calcification have often been seen. ${ }^{16}$

The synovial fluid is present in often large volume $^{16}$ with a low number of white blood cells, predominantly mononuclear cells, but frequently contains red blood cells and is often lightly blood stained. ${ }^{126-8}$ Collagenase and neutral protease activity has been found to be high in the synovial fluid. ${ }^{8} 9$ Hydroxyapatite crystals have also been detected in the synovial fluid from some of these joints. ${ }^{189}$

We describe the cases of two patients with apatite associated destructive arthropathy with shoulder involvement who have developed huge grossly haemorrhagic effusions that have ruptured spontaneously in the absence of collagenase activity in their synovial fluids.

\section{Case reports}

CASE 1

The patient was a 78 year old woman. In 1971 at the

Accepted for publication 25 November 1985.

Correspondence to Dr A D Woolf, Department of Medicine, Bristol Royal Infirmary, Bristol BS2 8HW. age of 64 years she developed a painful left shoulderco with no history of trauma. In 1977 she developeœ painful knees, and in 1980 her right shoulderi became symptomatic. There was rapid progressiore of damage in all four joints from 1980 onwards, ande by 1983 there was gross instability of the knees, bilateral ruptured rotator cuffs, large, cool effusionso in each joint, and severe pain and disability Radiographs showed attrition of articular cartilage and bone on both sides of the joint line; there was considerable loss of bone but little sclerosis oह osteophyte formation (Fig. 1), as described. previously. ${ }^{1}$ Large numbers of hydroxyapatite con $\frac{\mathscr{m}}{2}$ taining particles were detected by alizarin redo staining in synovial fluid from both shoulders and $\mathrm{B}$. both knees, ${ }^{10}$ and apatite associated destructive arthropathy was diagnosed.

Synovial biopsy of the left knee showed a papilo lary synovium with surface fibrin, hyperplastios synovial lining cells, and a patchy mononuclear cele infiltrate including plasma cells. Numerous hydroxy $\sim$ apatite crystals were identified in the superficial synovial tissue by analytical electron microscopy.

In January 1985 she spontaneously developed $x^{2}$ red 'raw meat' like area over the anterior aspect of the right shoulder, and within two days there was extensive bruising down the right upper arm (Fig 2). Right shoulder movement had become very painful. $250 \mathrm{ml}$ of heavily bloodstained fluid was aspirated from the right shoulder. Plain radiograph\% showed no change from previous films, bue arthrography demonstrated rupture of the shouldeo joint (Fig. 3). Nineteen days later a tense effusion o the right shoulder developed, from which a furthen 
$150 \mathrm{ml}$ of bloodstained fluid was aspirated, suggesting resealing of the shoulder joint. No collagenase activity was detected in the synovial fluid either before or after gel filtration, ${ }^{11}$ and $\beta$ glucuronidase and lactate levels were low. Synovial fluid findings are summarised in Table 1.

Coagulation tests were normal, buffy coat vitamin $\mathrm{C}$ was $71.5 \mu \mathrm{g} / 10^{8}$ white blood cells (WBC) (normal range 15-60). Routine haematological and biochemical screening tests were negative, and there was no evidence of intercurrent neurological or other disease.

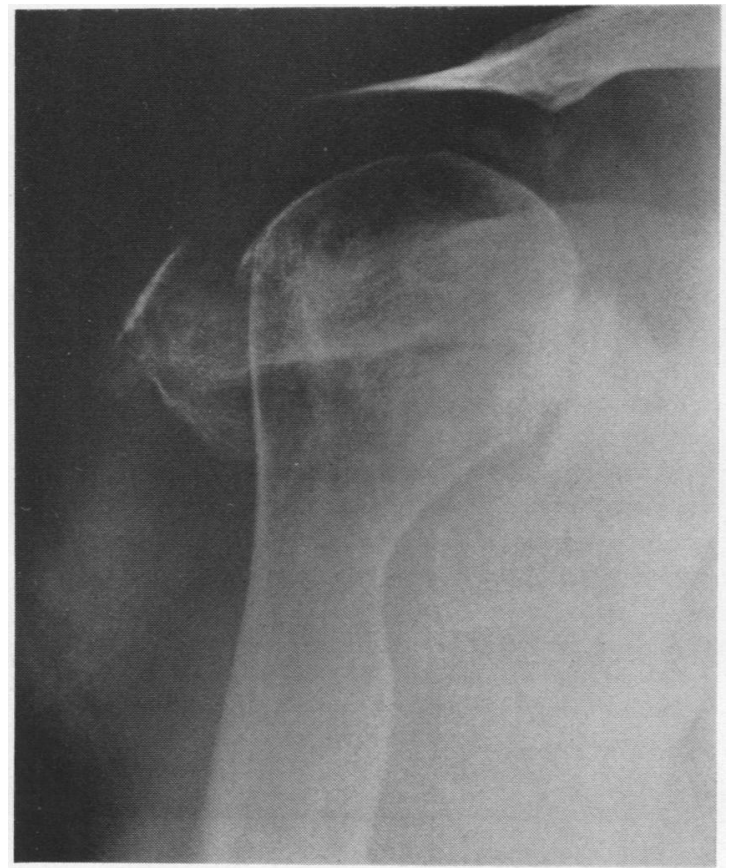

Fig. 1 x Ray of the right shoulder of case 1 .

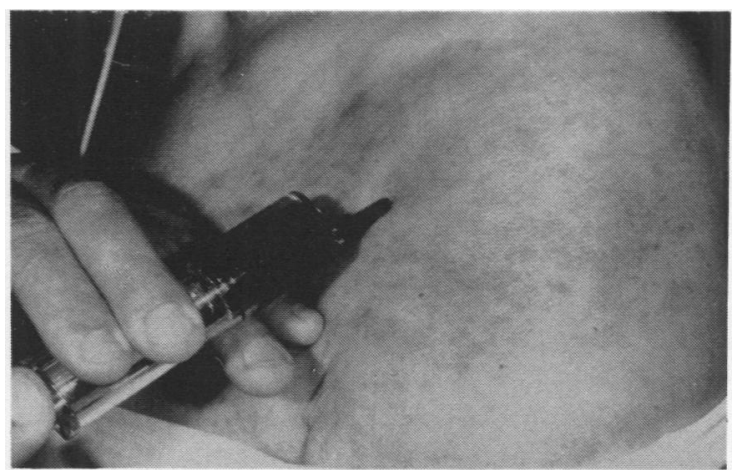

Fig. 2 Aspiration of heavily blood stained fluid and extensive bruising of the right shoulder of case 1 .
CASE 2

The patient was a 75 year old women. In 1978 at the age of 68 she fell, injuring her shoulders, which subsequently became painful. She also developed painful knees. In 1979 she spontaneously ruptured

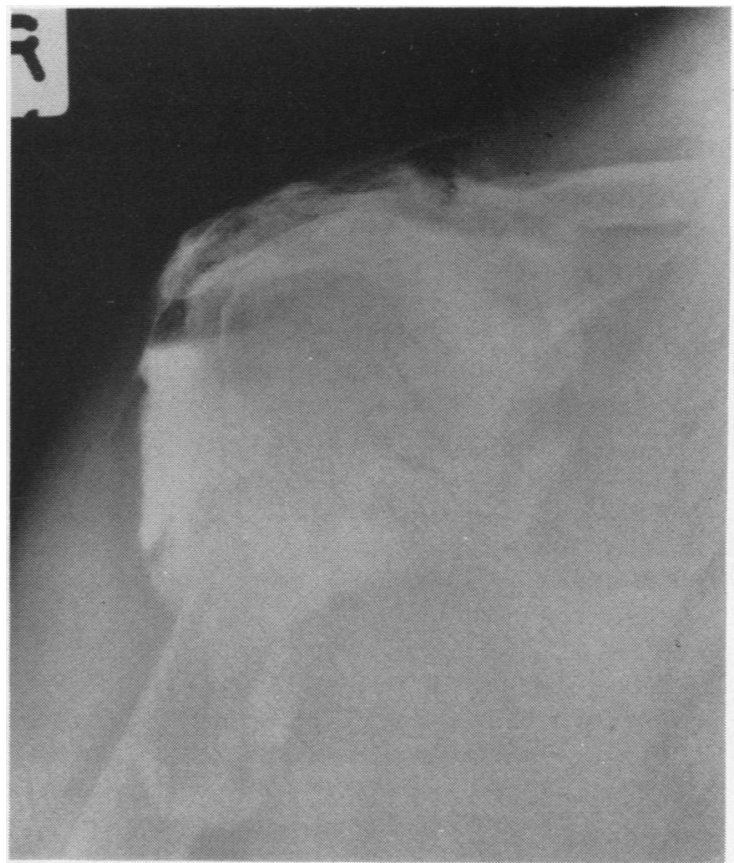

Fig. 3 Arthrogram of the right shoulder of case 1 demonstrating rupture of the shoulder joint.

Table 1 Synovial fluid findings: characteristics of synovial fluid at the time of shoulder rupture

\begin{tabular}{|c|c|c|}
\hline & Case No I & Case No 2 \\
\hline Volume (ml) & 150 & 70 \\
\hline Appearance & $\begin{array}{l}\text { Heavily } \\
\text { bloodstained }\end{array}$ & $\begin{array}{l}\text { Heavily } \\
\text { bloodstained }\end{array}$ \\
\hline Viscosity & High & High \\
\hline Clot formation & Negative & Negative \\
\hline Total white cell count & $<1 \times 10^{5} / \mathrm{ml}$ & $1 \times 10^{5} / \mathrm{ml}$ \\
\hline Differential & $\begin{array}{l}\text { Mainly } \\
\text { mononuclear }\end{array}$ & $90 \%$ mononuclear \\
\hline \multicolumn{3}{|l|}{ Cartilage fragments } \\
\hline$(0-3)$ & 1 & 2 \\
\hline Birefringent crystals & 0 & 0 \\
\hline $\begin{array}{l}\text { Alizarin red staining } \\
(0-3)\end{array}$ & $\begin{array}{l}2 \text { (large } \\
\text { ovoids) }\end{array}$ & $\begin{array}{l}3 \text { (large } \\
\text { ovoids) }\end{array}$ \\
\hline (OD) & $0 \cdot 20$ & 0.38 \\
\hline \multicolumn{3}{|l|}{ Lactic acid } \\
\hline$(\mathrm{mg} / 100 \mathrm{ml})^{*}$ & $5 \cdot 9$ & $2 \cdot 1$ \\
\hline Active collagenase & 0 & 0 \\
\hline Total collagenase & 0 & 0 \\
\hline
\end{tabular}

${ }^{*}$ SI conversion: $\mathrm{mg} / 100 \mathrm{ml} \times 0 \cdot 111=\mathrm{mmol} /$. 
her right shoulder cuff and subsequently the left in 1980. Radiology showed grossly damaged shoulders with large effusions. A Stanmore arthroplasty was performed on the right shoulder, which subsequently dislocated. By 1982 there was gross instability of both knees, with destruction of the lateral compartments and large effusions. Hydroxyapatite containing particles were detected by alizarin red staining in synovial fluid from both shoulders and both knees. Synovial biopsy of the right knee showed some densely cellular synovium, in part due to proliferation of fibroblasts, large multinucleate giant cells, and numerous deposits of hydroxyapatite. The clinical, radiological, and pathological features are therefore very similar to those of the first patient.

In August 1984 she spontaneously developed a large area of soft tissue bruising around the left shoulder with increasing pain on movement, and a large volume $(70 \mathrm{ml})$ of heavily bloodstained fluid was aspirated from the left shoulder. The synovial fluid findings are summarised in Table 1; they include a low total white cell count, numerous alizarin red staining particles, but no collagenase activity, and low levels of $\beta$ glucuronidase and lactate. Routine haematological and biochemical screening tests were normal, coagulation tests were normal, buffy coat vitamin C was $38.6 \mu \mathrm{g} / 10^{8}$ WBC.

The patient was otherwise well. The bruising on the arm became more extensive during the first week and extended laterally to the elbow. The shoulder was reaspirated twice, but after two weeks the pain and bruising slowly subsided.

\section{Discussion}

The destructive arthropathy with rotator cuff rupture of the shoulders in these two cases is similar to that previously described and variously labelled 'l'arthropathie destructrice rapide de l'épaule' (AD RE), 'Milwaukee shoulder', 'cuff-tear arthropathy', 7 'basic calcium phosphate crystal deposition disease', ${ }^{8}$ or 'apatite associated destructive arthritis'. ${ }^{1}$ Both patients also had destructive changes of the knees, as has been described elsewhere. ${ }^{18}$

Hydroxyapatite crystals were detected in the involved joints in both patients, as in some of the previously described cases. ${ }^{18}$ Hydroxyapatite crystals have also been found commonly in synovial fluid from patients with osteoarthritis ${ }^{12}$ and pyrophosphate arthropathy, ${ }^{13}$ and in small quantities in normals. ${ }^{14}$ The quantity of hydroxyapatite determined by alizarin red staining may be associated with the severity of the radiological changes of osteoarthritis, ${ }^{10}$ and heavy staining has been reported in destructive arthropathy. ${ }^{1}$ It is unclear, however, whether this is a crystal induced of associated disease.

Spontaneous haemarthrosis of the shoulder joinf has been previously described, ${ }^{35715}$ and on reviev some of these cases may have been apatite associ $\overline{\frac{\sigma}{\bar{T}}}$ ated destructive arthropathy, but synovial fluid were not examined for hydroxyapatite crystals Gross haemorrhagic effusion with spontaneous rup $\infty$ ture of the shoulder has not been previously noted ip described cases of apatite associated destructive arthritis, though fluids are often lightly blood stained. ${ }^{1} 68$ Haemorrhagic synovial effusions cap also occur in scurvy, but this was excluded in thes patients. Similarly, there was no evidence of ar coagulation defect, neurological disorder, or othe? intercurrent systemic or articular disease predisposece ing to the haemorrhagic joint rupture.

A striking feature of these and other describe $\frac{P}{\nexists}$ cases is the rapid progression of severe destructive changes in bone, cartilage, and periarticular tissues. The cause of this is unknown. It has been postulated that hydroxyapatite crystals are phagocytosed b $\overrightarrow{\&}$ synovial lining cells stimulating the secretion of collagenase and neutral protease. ${ }^{6} 816 \mathrm{We}$ therefore assayed these fluids for collagenase activity bote before and after gel filtration with a previousl described method that detects activity in som\& rheumatoid synovial effusions. ${ }^{11}$ No collagenas activity was found in either patient, though three separate samples were assayed from the first patien and two from the second. It therefore seems unlikely that generation of free collagenase was responsible for the joint attrition and rupture. The levels of $\beta$ glucuronidase and lactate (Table 1) were also low in comparison with the levels of inflammas tory fluids. ${ }^{14}$ No mechanism is yet apparent on examination of the patients, their synovial fluidsô and biopsy material.

Rapidly destructive disease of shoulder and kneg joints, in particular, is an important phenomenon in elderly, usually female, patients. These cases show. that spontaneous haemorrhagic rupture of thes shoulder can occur in this condition. Although rupture is associated with apatite crystals in the effusions, the role of the crystals is unclear. NO evidence for collagenase induced destruction was found.

We would like to thank the Arthritis and Rheumatism Council fæg financial support.

\section{References}

1 Dieppe $P$ A, Doherty M. Macfarlane D G, Hutton C US Bradfield J W, Watt I. Apatite associated destructive arthriti\$ Br J Rheumatol 1984; 23: 84-91.

2 Lequesne $N$, Fallut $M$, Coulomb R, Magnet J L, Strauss L'arthropathie destructrice rapide de l'épaule. Rev Rhum Mad Osteoartic 1982; 49: 427-37. 
3 de Seze S, Robault A, Rampon S. L'épaule sénile hémorragique. In: L'actualité Rhumatologique, 1967. Paris: Expansion Scientifique Francaise, 1968: 107-14.

4 Massias P, Sallièrre D, Clerc D, Languille D. L'arthropathie destructrice rapide de l'épaule. Rev Rhum Mal Osteoartic 1982; 49: $547-8$

5 Lamboley C, Bataille R, Rosenberg F, et al. L'épaule sénile hémorragique. Rhumatologie 1977: 323-30.

6 McCarty D J, Halverson P B. Carrera G F. Brewer B J, Kozin F. Milwaukee shoulder-association of microspheroids containing hydroxyapatite crystals, active collagenase and neutral protease with rotator cuff defects. I. Clinical aspects. Arthritis Rheum 1981; 24: 464-73.

7 Neer C S, Craig E V, Fukada H. Cuff-tear arthropathy. J Bone Joint Surg 1983; 65A: 1232-44.

8 Halverson P B, McCarty D J. Cheung H S, et al. Milwaukee shoulder syndrome: eleven additional cases with involvement of the knee in seven (basic calcium phosphate crystal deposition disease). Semin Arthritis Rheum 1984; 14: 36-44.

9 Halverson P B, Cheung H S. McCarty D J, Garancis J, Mandel N. Milwaukee shoulder-association of microspheroids containing hydroxyapatite crystals, active collagenase and neutral protease with rotator cuff defects. II. Synovial fluid studies. Arthritis Rheum 1981; 24: 474-83.

10 Paul H, Reginato A J, Schumacher H R. Alizarin red S staining as a screening test to detect calcium compounds in synovial fluid. Arthritis Rheum 1983; 26: 191-200.

11 Cawston T E, Mercer E. De Silva M, Hazelman B L. Metalloproteinases and collagenase inhibitors in rheumatoid synovial fluid. Arthritis Rheum 1984; 27: 285-90.

12 Dieppe P A. Crocker P. Huskisson E C, Willoughby D A. Apatite deposition disease: a new arthropathy. Lancet 1976; i: 266-70.

13 Dieppe P A. Doyle D V. Huskisson E C, Willoughby D A, Crocker P R. Mixed crystal deposition disease and osteoarthritis. Br Med J 1978; i: 150.

14 Fawthrop F, Hornby J, Swan A, et al. A comparison of normal and pathological synovial fluid. Br J Rheumatol 1985; 24: 61-9.

15 Banna A, Hume Kendall P. Spontaneous haemarthrosis of the shoulder joint. Ann Phys Med 1964; 7: 180-4.

16 Halverson P B. Cheung H S, McCarty D J. Enzymatic release of microspheroids containing hydroxyapatite crystals from synovium and of calcium pyrophosphate dihydrate crystals from cartilage. Ann Rheum Dis 1982; 41: 527-31. 